\title{
Evaluation Model of Environmental Governance Capacity Based on Social Network in Language Environment
}

\author{
Mengjun Meng ${ }^{1}$, Yingming Wang ${ }^{1,2 *}$ \\ ${ }^{1}$ Decision Sciences Institute, Fuzhou University, Fuzhou 350108, China \\ ${ }^{2}$ Key Laboratory of Spatial Data Mining \& Information Sharing of Ministry of Education, \\ Fuzhou University, Fuzhou 350108, China
}

Received: 23 August 2021

Accepted: 26 October 2021

\begin{abstract}
The problem of the evaluation of environmental governance capacity is an important issue in evaluating the improvement of ecological environment and the quality of economic development, but there are few evaluation models about environmental governance capacity. Considering the expression habits, the association and the psychological changes of experts, and the ambiguity of the decisionmaking environment, a consensus model for group decision making of 2-dimension 2-tuple linguistic information to express decision-making information in an empathy network environment is proposed in this paper. Firstly, confidence index is built by using the 2-dimension 2-tuple linguistic information. Secondly, the empathetic centrality incorporating the confidence index is used as induced value to gather expert decision information. The group consensus level is calculated by measuring the distance between individuals and groups, and a consensus adjustment method is established by using the confidence index. Next, the 2-dimension 2-tuple linguistic weighted averaging operator is used to process the group decision information that reaches consensus and obtain the evaluation results. Finally, an example of the evaluation of environmental governance capacity is used to prove the feasibility of the model, which can provide theoretical and method support for the problem of the evaluation of environmental governance capacity.
\end{abstract}

Keywords: 2-dimension 2-tuple linguistic information, confidence index, consensus reaching, empathetic relations, group decision making

\section{Introduction}

Group decision making is the process of gathering group members' preferences for solutions into

*e-mail: msymwang@hotmail.com a consensus or compromised group preference order according to some rules. Group members often consist of experts in the field, but due to the differences in knowledge structure, risk preferences, and psychological changes of experts, as well as the different decision contexts of different decision problems, experts ${ }^{6}$ evaluation results are often different. 
If we want to get the solution ordering that satisfies the group members, we need to make the experts come to an agreement $[1,2]$. Therefore, the focus of group decision making is on how to integrate the views of multiple group members, i.e., experts, into a group view, i.e., to achieve group consensus [3-5]. A lot of research has been done on group consensus, which mainly focuses on the solution of group consensus measurement and group consensus adjustment. In terms of consensus measurement, the metrics include distance measure [6-9], similarity measure [10, 11], order measure [12], and linear programming [13], etc. The decision makers choose different metrics based on different perspectives, such as the perspective of retaining as much original information as possible, the perspective of minimizing the number of iterations [14], the perspective of considering the psychological behavior of decision makers [15, 16], and so on. In terms of consensus adjustment, the main feedback mechanisms include interactive feedback models [17], local feedback models $[18,19]$, social network feedback models [20], and so on. Based on different adjustment objectives, it can be classified into minimum adjustment cost orientation [21], minimum adjustment element orientation [22], minimum adjustment distance orientation [23, 24], and maximum adjustment efficiency orientation [25], etc.

In the actual group decision making process, experts are not independent of each other, and they often come from the same field. There will be phenomena such as mutual contact, mutual concern and mutual appreciation, and this social relationship will have an important impact on the decision outcome. For example, in a certain evaluation process of water pollution control capacity, expert A is the authority in the field, and then in the process of reaching consensus, other experts are more inclined to accept A's opinion. Another example is that in the decision-making process, if it is known that expert A prefers a solution, expert B may also pay more attention to that solution. The utility of an individual decision making maker regarding a decision solution depends not only on the real preferences of the individual decision making maker, but is also related to the preferences of certain other individual decision making makers in the decision group. In economics, an individual's understanding of others' emotions and concern for others' welfare is called empathy [26]. Social relationships based on empathy in group decision making are called empathetic relations, and the network formed by all empathetic relations in a group is called an empathy network [27]. Salehi-Abari et al. [28] scholars first proposed the linguistic terms, which proposed a research framework and various properties of empathetic relations. Yao Shengbao et al. [27] used intuitionistic fuzzy preference relations to express decision information, and proposed a consensus model for group decision making with the global empathetic model as a perspective. However, there are fewer studies on group decision making in the context of empathetic relations.
Considering the ambiguity of human thinking and the complexity of the decision-making environment, the expression form of linguistic phrases is more in line with the expert's cognition and close to the actual situation of group decision making decisions. Zadeh [29] first proposed the concept of linguistic variable, i.e., using linguistic phrases such as good, very good, and mediocre to express the evaluation information. Herrera [30] et al. proposed the concept of 2-tuple linguistic information on this basis, which quantifies the decision information while avoiding the loss and distortion of information. Zhu Weidong, Zhou Guangzhong and Yang Shanlin first put forward the concept of two-dimensional language evaluation information. The first dimensional information is used to express the linguistic evaluation value of the decision object and the second dimensional information is used to express the subjective credibility of the first dimensional information, which makes the expression of evaluation information more intuitive, accurate, and perfect. Therefore, in this paper, the 2-dimension 2-tuple linguistic information will be used to process the decision information.

The evaluation of environmental governance capacity is a multi-attribute group decision making problem. Its decision subject is generally the government, and the decision problem to be solved is the ordering of governance capacity. The current research on environmental governance capacity mainly focuses on influencing factors, including economic factors [32, 33], social factors [34, 35], human factors $[36,37]$, technical factors [38], and institutional factors [39], demographic factors [40], land use patterns $[41,42]$. Some administrative units use open-source software to obtain information to solve problems [43]. However, among the current research results, there is little literature on evaluation methods.

Environmental governance capability evaluation is a systematic evaluation problem, which involves a wide range. It is difficult for evaluation experts to comprehensively master the relevant knowledge or understand the relevant information. At the same time, evaluation experts are likely affected by other experts instead of independently to make decisions. In this paper, the evaluation of environmental governance ability is regarded as a social network group decisionmaking problem, and a consensus model for group decision making of 2-dimension 2-tuple linguistic information under the influence of empathetic relations is constructed to solve a series of problems. Firstly, 2-dimension 2-tuple linguistic information is used to represent the decision information and describe the decision problem. Then, a consensus model for group decision making is proposed based on empathy network and confidence index. Finally, the effectiveness and feasibility of the proposed method are verified by example analysis of the evaluation of environmental governance capacity. The main contributions of this paper consist of three aspects. Firstly, the empathetic 
relations are extended to the field of linguistic decision making, making its application scenarios more in line with the reality of the management decision. Secondly, the psychological changes of decision makers are expressed in the form of confidence indices and combined with empathetic relations to make the decision-making process more realistic and effective. Thirdly, combining the information index with the feedback mechanism can provide as much feedback information to the experts as possible, which is convenient for them to modify the information and achieve group consensus.

\section{Preliminaries}

\section{2-tuple Linguistic Representation Model}

Definition 1 [30] $S=\left\{S_{0}, S_{1}, \ldots, S_{g}\right\}, S_{i} \in S$ is a set of linguistic terms, and then 2-tuple linguistic information can be obtained by the following function.

$$
\begin{aligned}
& \phi: S \rightarrow S \times[-0.5,0.5) \\
& \phi:\left(S_{i}\right) \rightarrow\left(S_{i}, 0\right), S_{i} \in S
\end{aligned}
$$

Definition 2 [30] $\beta \in[0, g]$ is the set of linguistic phrase evaluations; $S=\left\{S_{0}, S_{1}, \ldots, S_{g}\right\}$ is the real number obtained by a kind of set operation; and then $\beta$ can be expressed as a 2-tuple linguistic information by the following function $\Delta$.

$$
\begin{gathered}
\Delta:[0, g] \rightarrow S \times[-0.5,0.5) ; \\
\Delta(\beta)=\left\{\begin{array}{c}
S_{i}, i=\operatorname{round}(\beta) ; \\
\alpha_{i}=\beta-i, \alpha_{i} \in[-0.5,0.5) .
\end{array}\right.
\end{gathered}
$$

Where round is a rounding operator.

Definition 3 [30] $S=\left\{S_{0}, S_{1}, \ldots, S_{g}\right\}, S_{i} \in S$, $\alpha_{i} \in[-0.5,0.5),\left(S_{i}, \alpha_{i}\right)$ is a 2-tuple linguistic information, then there exists an inverse function $\Delta^{-1}$ that converts it to the corresponding real number $\beta \in[0, g]$, i.e.

$$
\begin{gathered}
\Delta^{-1}: S \times[-0.5,0.5) \rightarrow[0, g] ; \\
\Delta^{-1}\left(S_{i}, \alpha_{i}\right)=i+\alpha_{i}=\beta .
\end{gathered}
$$

Definition 4 [30] For any two 2-tuple linguistic information, the rule of comparison between them is as follows.

(1) If $i>j$, then $\left(S_{i}, \alpha_{i}\right)>\left(S_{j}, \alpha_{j}\right)$.

(2) If $i=j$, when $\alpha_{i}>\alpha_{j},\left(S_{i}, \alpha_{i}\right)>\left(S_{j}, \alpha_{j}\right)$; when $\alpha_{i}<\alpha_{j}$, $\left(S_{i}, \alpha_{i}\right)<\left(S_{j}, \alpha_{j}\right)$; and when $\alpha_{i}=\alpha_{j},\left(S_{i}, \alpha_{i}\right)=\left(S_{j}, \alpha_{j}\right)$.

For example, $S=\left\{s_{0}=\right.$ very poor, $s_{1}=$ poor, $s_{2}=$ medium, $s_{3}=$ good, $s_{4}=$ very good $\}$ is a 5-granularity set of linguistic terms, and then the corresponding 2-tuple linguistic information is $\Delta(2.6)=\left(s_{3},-0.4\right)$ when $\beta=2.6$. Conversely, and the value corresponding to the 2-tuple linguistic information $\left(s_{3},-0.4\right)$ is $\Delta^{-1}\left(s_{3},-0.4\right)=2.6$.

\section{2-dimension 2-tuple Linguistic Representation Model}

In contrast to 2-tuple linguistic information, 2-dimension 2-tuple linguistic information uses two dimensions to express decision information. The first dimensional information represents the evaluation of the thing itself, and the second dimensional information represents the degree of certainty of the information in the first dimension.

Definition 5 [31] $S=\left\{s_{0}, s_{1}, \ldots, s_{h_{1}}\right\}$ is the set of linguistic evaluation information in the first dimension; $S^{*}=\left\{s_{0}{ }_{0}, s^{*}, \ldots, s^{*}{ }_{h}\right\}$ is the set of linguistic evaluation information in the second dimension, and then the 2-dimension 2-tuple linguistic information is represented as $\tilde{S}_{t}=\left(\left(s_{i_{t}}, \alpha_{i_{t}}\right),\left(s_{i_{t}}^{*}, \alpha_{j}^{*}\right)\right)$, where $\alpha_{i_{t}} \in[-0.5$, $0.5), \alpha_{i_{t}}^{*} \in[-0.5,0.5)$. In particular, when $\alpha_{i_{t}} \stackrel{i_{t}}{=} \alpha_{i_{t}}^{*}=0$, $\tilde{S}_{t}$ degenerates to $\left(S_{i}, S_{j}^{*}\right)$.

Definition 6 [44] If $\tilde{S}_{t_{1}}=\left(\left(s_{i_{11} 1}, \alpha_{i_{t 1}}\right),\left(s_{j_{t 1}}^{*}, \alpha_{j_{t 1}}^{*}\right)\right)$, $\tilde{S}_{t_{2}}=\left(\left(s_{i_{t 2}}, \alpha_{i_{t_{2}}}\right),\left(s_{j_{t 2}}^{*}, \alpha_{j_{t 2}}^{*}\right)\right), \ldots, \tilde{S}_{t_{n}}=\left(\left(s_{i_{t y}}, \alpha_{i_{t_{n}}}\right),\left(s_{j_{t_{n}}}^{i_{t}}, \alpha_{j_{t_{t}}}^{t_{t 1}}\right)\right)$ is a set of 2-dimension 2-tuple linguistic ${ }^{t_{n}}$ information and $\omega_{t}=\left(\omega_{t,}, \omega_{t_{2}}, \ldots, \omega_{t}\right)^{T}$ is its corresponding weight vector, then the weighted averaging operator is of $\omega_{t}=$ $\left(\omega_{t_{1}}, \omega_{t_{2}}, \ldots, \omega_{t_{n}}\right)^{T}$ is:

$$
2 D L W A A\left(\tilde{S}_{t_{1}}, \tilde{S}_{t_{2}}, \mathrm{~L} \tilde{S}_{t_{n}}\right)=\Delta\left(\sum_{q=1}^{n} \omega_{t_{q}} \Delta^{-1}\left(S_{i_{t_{q}}}, \alpha_{i_{t_{q}}}\right), \sum_{q=1}^{n} \omega_{t_{q}} \Delta^{-1}\left(S_{j_{t_{q}}}^{*}, \alpha_{j_{t_{q}}}^{*}\right)\right)
$$

For example, $S=\left\{s_{0}=\right.$ very poor, $s_{1}=$ poor, $s_{2}=$ medium, $s_{3}=\operatorname{good}, s_{4}=$ very good $\}$ is the firstdimensional linguistic term set; $S^{*}=\left\{s_{0}{ }_{0}=\right.$ unsure, $s_{1}^{*}=$ little sure, $s_{2}{ }_{2}=$ sure, $s_{3}^{*}=$ very sure, $s_{4}{ }_{4}=$ higly sure $\}$ is the second-dimensional linguistic term set, and 2-dimension 2-tuple linguistic information $\tilde{S}=\left(\left(s_{3}, 0.3\right)\right.$, $\left.\left(s_{3}^{*}, 0.2\right)\right)$ indicates that the expert has a relatively good reason to give a good evaluation.

\section{Empathy Networks}

Individuals' understanding of others' emotions and concern for others' welfare are called empathy [26]. Social relationships based on empathy in group decision making are called empathetic relations, and the network formed by all empathetic relations in a group is called an empathy network [27].

Definition 7 [27, 28] An empathy network is a directed assignment graph used to describe the empathetic relations in a group, denoted as $G(N$, $A$ ), where $N=\{1,2, \ldots, m\}$ denotes group members, $A=(a(i, j)$ denotes group member $i$ has empathetic relations with group member $j$. The weight information on the directed arc is the empathy weight, whose magnitude represents the intensity of group member 
$i$ 's attention to group member $j$. For group member $e_{i}$, the empathy weight satisfies $w_{i i}+\sum_{j \neq i} w_{i j}=1$, where $w_{i i}$ is called the weight of group member $i$ in adhering to personal opinion. In general, $\forall i \in N$, and therefore $w_{i i}>0$.

Definition 8 [27, 28] In an empathy network, the empathetic centrality is used to characterize the centrality of a node. In the empathy network $G(N$, $A), \forall j \in N$, if $A(j)=\{i \neq j \mid a(i, j) \in A\}, E C_{j}=w_{j j}+\sum_{i \in A(j)} w_{i j}$ is called the empathetic centrality of node $j$. Obviously, the greater the empathetic centrality of a node, the more important the node is in the empathy network, and the more likely the expert opinion represented by that point is valued and accepted by other experts. Since $\forall i, w_{i i}+\sum_{j \neq i} w_{i j}=1, w_{i i}>0$, and $E C_{j} \in(0, m)$, then $\sum_{j=1}^{m} E C_{j}=m$.

For example, the Fig. 1 shows the empathy network in normal circumstances, where $N=\{1,2,3,4\}$ is four experts, $W=\left(w_{i j}\right)_{m \times m}$ denoting the empathy weight matrix.

$$
W=\left(\begin{array}{cccc}
0.8 & 0.1 & 0 & 0.1 \\
0.3 & 0.6 & 0.1 & 0 \\
0.3 & 0 & 0.5 & 0.2 \\
0.3 & 0.1 & 0.2 & 0.4
\end{array}\right)
$$

It is easy to see that the sum of the elements in row $i$ of the empathy weight matrix $W=\left(w_{i j}\right)_{m \times m}$ is 1 , i.e. $w_{i i}+\sum_{j \neq i} w_{i j}=1$; the sum of the elements in column $j$ is the empathetic centrality of node $j$. The values of empathetic centrality of the four experts in order are $E C_{1}=1.7, E C_{2}=0.8, E C_{3}=0.8, E C_{4}=0.7$; thus it can be seen that expert 1 is the most trusted and occupies the most important position in the decision-making process.

\section{A Consensus Model for Group Decision Making of 2-dimension 2-tuple Linguistic Information Based on Empathetic Relations}

Considering a consensus of group decision problem expressed by 2-dimension 2-tuple linguistic



Fig. 1. Empathy network. information, with $m$ experts $e_{k}(k=1,2,3, \ldots, m)$, giving evaluation values for $\mathrm{n}$ alternatives $x_{p}(p=1,2,3, \ldots$, $n)$ and $r$ attributes $c_{q}(q=1,2,3, \ldots, r)$. The evaluation information is expressed by 2-dimension 2-tuple linguistic information. The first dimensional 2-tuple linguistic information indicates the leave-taking of the thing itself, and the 2-tuple linguistic information providing linguistic evaluation information is $S=\left\{s_{0}\right.$, $\left.s_{1}, \ldots, s_{g}\right\}$. The second dimensional 2-tuple linguistic information indicates the degree of certainty about the first dimensional information, and the linguistic phrase providing credibility is $\dot{S}=\left\{\dot{s_{0}}, \dot{s_{1}}, \ldots, \dot{s}_{h}\right\}, \quad s_{u_{p q}}^{k} \in S, s_{v_{p q}}^{k} \in \dot{S}$, $S=\left(\left(s_{u_{p q}}^{k}, \alpha_{u_{p q}}^{k}\right),\left(s_{v_{p q}}^{k}, \alpha_{v_{p q}^{k}}^{k}\right)\right)$ indicating a 2-tuple linguistic information, where $\quad \alpha_{u_{p q}}^{k} \in[-0.5,0.5), \alpha_{v_{p q}}^{k} \in[-0.5,0.5)$. The 2-dimension 2-tuple linguistic information evaluation matrix provided by the expert $e_{k}$ is $M_{k}=\left(\left(S_{u_{p q}}^{k}, \alpha_{u_{p q}}^{k}\right),\left(S_{v_{p q}}^{\dot{k}}, \alpha_{v_{p q}}^{k}\right)\right)_{n \times l}$. Denote that the expert weight is $\eta=\left(\eta_{1}, \eta_{2}, \ldots, \eta_{m}\right)^{T}$, and the attribute weight is $\omega=\left(\omega_{1}, \omega_{2}, \ldots, \omega_{r}\right)^{T}$. The empathetic centrality of the expert is $E C=\left\{E C_{1}, E C_{2}, \ldots, E C_{m}\right\}$.

Due to the expert variability and the ambiguity of the decision context, an important step in the group decision process is group consistency analysis, also known as consensus analysis. The group consensus process is the process of convergence of opinions through continuous adjustment of group members opinions [45-50]. The group decision making problem guided by empathetic relations requires consideration of the relationship between experts and the process of experts' psychological changes in the process of reaching a consensus. This section uses the empathetic centrality adjusted by confidence index as the induced value to gather the results of group decision making. Then the distance between individual decision making and group decision is calculated to derive the consensus level, and then the feedback mechanism is used to identify the most deviant value of the expert and adjust it to reach the set threshold, and finally the group decision is made on the basis of achieving consistency.

\section{Gathering Information for Group Decision Making}

One problem to consider before gathering group decision information is whether the empathetic centrality is simply the sum of the expert's selfidentification weight and the empathy weight of others toward that expert. The empathetic centrality represents the importance of the node in the empathy network, and only objective factors are considered in this passive summation. But subjectively, how confident the expert is in his or her own opinion also has an impact on his or her status in the network. For example, if an expert is very confident in his or her own decisions, he or she will magnify his or her own opinions and ignore the influence of others on him or her, and the empathetic centrality of the node represented by that expert will 
change. In this section, the empathetic centrality is moderated by using the confidence index.

The 2-dimension 2-tuple linguistic information is represented as $\left(\left(s_{u_{p q}}^{k}, \alpha_{u_{p q}}^{k}\right),\left(s_{v_{p q}}^{k}, \alpha_{v_{p q}}^{k}\right)\right)$; the second dimensional information indicates the degree of certainty about the information of the first dimension. The second second dimensional information is used to build the expert confidence index. Let $\rho_{k}$ be a power function, which means that its utility is monotonically increasing and its first-order derivative is monotonically decreasing.

$$
\begin{aligned}
\rho_{k} & =C F_{k}^{\gamma} \\
& =\left(\sum_{p=1}^{n} \sum_{q=1}^{l}\left(v_{p q}^{\dot{k}}+\alpha_{p q}^{\dot{k}}\right)\right)^{\gamma}
\end{aligned}
$$

Among them, $\gamma$ is the confidence coefficient $(0<\gamma<1)$. Obviously, $0 \leq \rho_{k} \leq 1$; the larger the $C F_{k}$ is, the more confident the expert $e_{k}$ is in his own opinion; he/she is less likely to be influenced by the surrounding concerns. The smaller the $C F_{k}$ is, the standard expert is more likely to amplify the concerns of others about him/her.

The adjusted empathetic centrality is:

$$
E C_{k}^{*}=\rho w_{k k}+(1-\rho) \sum_{i \in A(k)} w_{i k}
$$

The IOWA operator $\phi_{\eta}^{E C^{*}}$ with empathetic centrality as the induced value, i.e., the $E C^{*}$-OIWA operator gathers individual decision making information to form group decision linguistic information.

Firstly, by referring to the practices of Yager R [51] and Yao Shengbao [27], the weights when gathering individual decision making information are calculated with $\eta_{\sigma(h)}=\left(\eta_{\sigma(1)}, \eta_{\sigma(2)}, \ldots, \eta_{\sigma(m)}\right)^{T}, \eta_{\sigma(h)} \in(0,1), \sum_{h=1}^{m} \eta_{\sigma(h)}=1$, and the $\eta_{\sigma(h)}$ represents the weights of the attribute values given by the experts corresponding to the $h t h$ largest $E C^{*}$ value.

$$
\begin{gathered}
\eta_{\sigma(h)}^{E C}=Q\left(\frac{h}{m}\right)-Q\left(\frac{h-1}{m}\right), h=1,2, \ldots, m \\
Q(r)=r^{\delta}
\end{gathered}
$$

$\delta$ is called the empathetic attitude parameter, which assigns different weights to the $E C^{*}-O I W A$ operator. When $\delta=1, \eta^{E C^{*}}=\left(\frac{1}{m}, \frac{1}{m}, \ldots, \frac{1}{m}\right)$; when $\delta=+\infty, \eta^{E C^{*}}=(0$, $0, \ldots, 1)$; when $\delta \in(0,1), \eta_{\sigma(m)}^{E C^{*}} \leq \cdots \leq \eta_{\sigma(2)}^{E C^{*}} \leq \eta_{\sigma(1)}^{E C^{\prime}} ;$; and when $\delta \in(1,+\infty), \eta_{\sigma(1)}^{E C^{*}} \leq \eta_{\sigma(2)}^{E C^{*}} \leq \ldots \leq \eta_{\sigma(n)}^{E C^{*}}$.

Group information is gathered as:

$$
\begin{gathered}
\Delta^{-1}\left(S_{u_{p q}}^{c}, \alpha_{u_{p q}}^{c}\right)=\phi_{\eta}^{E C^{*}}\left(\left\langle E C_{1}^{*}, \Delta^{-1}\left(S_{u_{p q}}^{1}, \alpha_{u_{p q}}^{1}\right)\right\rangle,\left\langle E C^{*} \Delta_{2}^{* 1}\left(S_{u_{p q}}^{2}, \alpha_{u_{p q}}^{2}\right)\right\rangle, \cdots,\right. \\
\left.\left\langle E C_{m}^{*}, \Delta^{-1}\left(S_{u_{p q}}^{m}, \alpha_{u_{p q}}^{m}\right)\right\rangle\right)=\sum_{h=1}^{m} \eta_{\sigma(k)}^{E C^{*}} \Delta^{-1}\left(S_{u_{p q}}^{\sigma(h)}, \alpha_{u_{p q}}^{\sigma(h)}\right)
\end{gathered}
$$

$$
\begin{gathered}
\Delta^{-1}\left(s_{v_{p q}}^{i}, \alpha_{v_{p q}}^{i}\right)=\phi_{\eta}^{E C^{c}}\left(\left\langle E C_{1}^{*}, \Delta^{-1}\left(S_{v_{p q}}^{\mathrm{i}}, \alpha_{v_{p q}}^{\mathrm{i}}\right)\right\rangle,\left\langle E C_{2}^{*}, \Delta^{-1}\left(S_{v_{p q}}^{\dot{i}}, \alpha_{v_{p q}}^{i}\right)\right\rangle, \ldots,\right. \\
\left.\left\langle E C_{m}^{*}, \Delta^{-1}\left(S_{v_{p q}}^{\dot{m}}, \alpha_{v_{p q}}^{\dot{m}}\right)\right\rangle\right)=\sum_{h=1}^{m} \eta_{\sigma(k)}^{E C^{*}} \Delta^{-1}\left(S_{v_{p q}}^{\dot{\sigma}(h)}, \alpha_{v_{p q}}^{\sigma^{*}(h)}\right)
\end{gathered}
$$

The group decision making matrix is:

$$
\begin{aligned}
M_{c} & =\left(\left(s_{u_{p q}}^{c}, \alpha_{u_{p q}}^{c}\right),\left(s_{v_{p q}}^{i}, \alpha_{v_{p q}}^{i}\right)\right)_{p \times q} \\
& =\left(\Delta^{-1}\left(s_{u_{p q}}^{c}, \alpha_{u_{p q}}^{c}\right), \Delta^{-1}\left(s_{p_{p q}}^{i}, \alpha_{p_{p q}}^{i}\right)\right)_{p \times q}
\end{aligned}
$$

Where $E C_{\sigma(h-1)} \leq E C_{\sigma(h)}, 0 \leq \eta_{\sigma(h-1)}^{E C} \leq \eta_{\sigma(h)}^{E C}, \sum_{h=1}^{m} \eta_{\sigma(h)}^{E C}=1$

\section{Consensus Level Measurement}

In this section, the distance between individual decision making-making and group decision making is used to measure the level of group consensus. The linguistic expression information of individual decision making-making is $S^{k}=\left(\left(S_{u_{p q}}^{k}, \alpha_{u_{p q}}^{k}\right),\left(S_{v_{p q}}^{k}, \alpha_{v_{p q}}^{k}\right)\right)$, and the linguistic expression information of group decision making gathered in the previous section is $S^{c}=\left(\left(s_{u_{p q}}^{c}, \alpha_{u_{p q}}^{c}\right),\left(s_{v_{p q}}^{i}, \alpha_{v_{p q}}^{i}\right)\right)$, and the distance between them is $d\left(S^{c}, S^{k}\right)[52]$.

$$
d\left(S^{c}, S^{k}\right)=\left(\varepsilon\left|x_{c}-x_{k}\right|^{2}+(1-\varepsilon)\left|y_{c}-y_{k}\right|^{2}\right)^{\frac{1}{\lambda}}
$$

Where $\quad x_{c}=\frac{u_{p q}^{c}+\alpha_{p q}^{c}}{g}, \quad x_{k}=\frac{u_{p q}^{k}+\alpha_{p q}^{k}}{g}, \quad y_{c}=\frac{v_{p q}^{c}+\alpha_{p q}^{c}}{h}$, $y_{k}=\frac{u_{p q}^{k}+\alpha_{p q}^{k}}{g}$

When $\lambda=1, d\left(S^{c}, S^{k}\right)$ is the Hamming distance, and when $\lambda=2, d\left(S^{c}, S^{k}\right)$ is the Euclidean distance.

The individual consensus is:

$$
C I_{k}=1-d\left(S^{c}, S^{k}\right)
$$

The expert weight is:

$$
\eta_{k}=\frac{E C_{k}^{*}}{m}
$$

The group consensus is:

$$
G C I=\sum_{k=1}^{m} \eta_{k} C I_{k}
$$


In the actual decision-making process, the threshold value $\tau$ of group consensus level is usually set in advance. If $G C I \geq \tau$, then it indicates that group consensus is reached; if $G C I \leq \tau$, then it indicates that there are differences in group opinions, and the feedback mechanism needs to be activated to improve the group consensus level by adjusting the decision results of group members.

\section{Feedback Mechanism}

In the feedback mechanism, firstly, it is necessary to identify the members who need to adjust their decisions, and the identification rule is the member with the smallest individual consensus, i.e., the member with the farthest distance from the result of the group decision making.

$$
e_{k}^{a d j}=\max \left\{d\left(S^{c}, S^{k}\right)\right\}
$$

Since group members tend to accept the assumption that they have preferences to whom they have empathetic relations, this section establishes adjustment rules by using empathetic relations as an important source of information for the adjustment of suggestions. The adjusted decision matrix $M_{k}^{l+1}$ of $e_{k}^{a d j}$ is:

$$
M_{k}^{l+1}=\theta M_{k}^{l}+\frac{(1-\theta)}{2}\left(M_{k j}+M_{c}\right)
$$

where $M_{k}^{l}$ is the decision matrix of $e_{k}^{a d j}, M_{k j}$ is the set of decision matrices of empathetic subjects, $M_{c}$ is the group decision making matrix, and $\theta$ is the feedback adjustment coefficient. $\theta$ represents the weight of own decision information of $e_{k}^{a d j}$, and the confidence index $\rho_{k}(k=1,2, \ldots, m)$ above represents the expert's reliability of his own decision information, which can be expressed by $\rho_{k}\left(\theta=\rho_{k}\right)$.

\section{Solution Ordering}

The group decision making matrix for reaching agreement is:

$$
M_{c}^{*}=\left(\left(s_{p q}, \alpha_{p q}\right),\left(\dot{s}_{p q}, \dot{\alpha}_{p q}\right)\right)_{p \times q}
$$

The decision information for each solution is gathered by using a 2-dimension 2-tuple linguistic information weighted averaging operator, and the evaluation value of the solution $X_{p}$ is:

$2 D L W A A\left(S_{p 1}, S_{p 1}, \ldots, S_{p r}\right)=\Delta\left(\sum_{q=1}^{r} \omega_{p q} \Delta^{-1}\left(S_{p q}, \alpha_{p q}\right), \sum_{q=1}^{r} \omega_{p q} \Delta^{-1}\left(\dot{S}_{p q}, \dot{\alpha}_{p q}\right)\right)$

Calculate its expected value and rank the solutions, and the expected value is [53]:

$$
E\left(S_{p}\right)=\frac{\Delta^{-1}\left(S_{p q}, \alpha_{p q}\right)}{g} \times \frac{\Delta^{-1}\left(\dot{S}_{p q}, \dot{\alpha}_{p q}\right)}{h}
$$

Solution ordering can be performed based on the magnitude of the expected value.

The process of a consensus model for group decision making of 2-dimension 2-tuple linguistic information based on empathetic relations is as follows.

Input: the experts' decision matrix $M_{k}=\left(m_{p q}^{k}\right)_{r \times r}=\left(\left(s_{u_{p q}}^{\dot{k}}, \alpha_{u_{p q}}^{\dot{k}}\right),\left(s_{v_{p q}}^{\dot{k}}, \alpha_{v_{p q}}^{\dot{k}}\right)\right)_{n \times r}, \quad$ experts' empathy adjacency matrix $W=\left(w_{i j}\right)_{m \times m}$, threshold $\tau$ for group consensus level, empathetic attitude parameter $\delta$, distance adjustment parameter $\varepsilon$, feedback adjustment coefficient $\theta$.

Output: the optimal solution $x_{o p i}$

Step 1. Let $l=0$, construct the confidence index according to equation (8), calculate the adjusted empathetic centrality according to equation (9), and calculate the group decision making matrix according to Equation (10)-Equation (14).

Step 2. Calculate the distance $d\left(S^{c}, S^{k}\right)$ between the individual decision making matrix and the group decision making matrix according to Equation (15).

Step 3. Calculate the group consensus level $G C I^{(1)}$, 1 according to Equation (16)-Equation (18). If $G C I^{(1)} \geq \tau$, go to step 7; if $G C I^{(1)} \leq \tau$, go to step 4 .

Step 4. Identify the individual $e_{k}^{a d j}$ to be adjusted according to Equation (19).

Step 5. Adjust the decision information of the individual $e_{k}^{a d j}$ according to Equation (20). Let $l=l+1$, and then go to step 1.

Step 6. Calculate the expected value $E\left(S_{p}\right)$ of each solution in the group decision matrix $M_{c}^{l}$ according to Equation. (21)-Equation. (23) and determine the optimal solution.

\section{A Consensus Model for Group Decision Making of Environmental Governance Capacity Based on Empathetic Relations}

A government agency invites five experts $e_{1}, e_{2}, e_{3}$, $e_{4}$, and $e_{5}$ in the field of environmental governance to evaluate the environmental governance capacity of three cities $x_{1}, x_{2}, x_{3}$. After discussion, the experts will evaluate them from four aspects: regulations and policies $c_{1}$, corporate responsibility $c_{2}$, risk prevention and control $c_{3}$, and governance costs $c_{4}$. The linguistic evaluation set for attribute values is $S=\left\{s_{0}=\right.$ highly poor, $s_{1}=$ very poor, $s_{2}=$ poor, $s_{3}=$ medium, $s_{4}=$ good, $s_{5}=$ very good, $s_{6}=$ highly good $\}$, and the linguistic evaluation set for certainty is $\dot{S}=\left\{\dot{s}_{0}=\right.$ unsure, $\dot{s}_{1}=$ little sure,$\dot{s}_{2}=$ sure,$\dot{s}_{3}=$ very sure,$\dot{s}_{4}=$ highly sure $\}$.

The evaluation matrices given by 5 experts for different environmental governance situations are shown in Table 1 . 


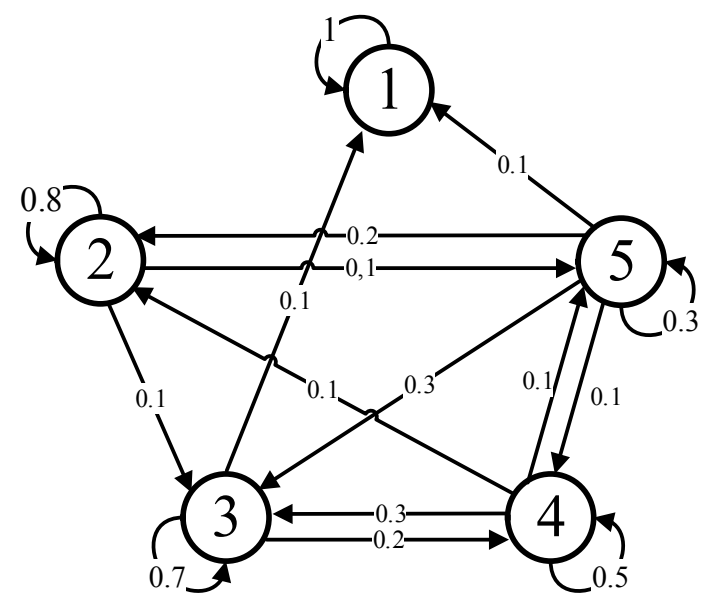

Fig. 2. Empathy network of the 5 experts.

Since the five experts were from the same field and knew each other, the corresponding empathy network is:
The empathy matrix $W=\left(w_{i j}\right)_{m \times m}$ is:

$$
W=\left(\begin{array}{ccccc}
1 & 0 & 0 & 0 & 0 \\
0 & 0.8 & 0.1 & 0 & 0.1 \\
0.1 & 0 & 0.7 & 0.2 & 0 \\
0 & 0.1 & 0.3 & 0.5 & 0.1 \\
0.1 & 0.2 & 0.3 & 0.1 & 0.3
\end{array}\right)
$$

Step 1. Calculate the group decision making matrix according to Equation (8)-Equation (14).

Firstly, calculate and gather the induced value of the individual decision making matrix, i.e., the empathy centrality $E C_{k}{ }^{*}$ of each expert. Let the confidence coefficient $\gamma=0.3$.

$$
\begin{aligned}
E C_{k}^{*} & =\rho w_{k k}+(1-\rho) \sum w_{i k} \\
& =C F_{k}^{0.3} w_{k k}+\left(1-C F_{k}^{0.3}\right) \sum w_{i k}
\end{aligned}
$$

The empathetic centrality of each expert is $E C_{1}{ }^{*}=0.4568, E C_{2}{ }^{*}=0.4409, E C_{3}{ }^{*}=0.7, E C_{4}{ }^{*}=0.3482$, $E C_{5}^{*}=0.2204$.

Then, calculate the weights $\eta_{\sigma(h)}=\left(\eta_{\sigma(1)}, \eta_{\sigma(2)}, \ldots, \eta_{\sigma(m)}\right)^{T}$,

\begin{tabular}{|c|c|c|c|c|c|}
\hline & & $c_{1}$ & $c_{2}$ & $c_{3}$ & $c_{4}$ \\
\hline \multirow[t]{3}{*}{$e_{1}$} & $x_{1}$ & $\left(\left(s_{5}, 0.3\right),\left(s_{4}, 0\right)\right)$ & $\left(\left(s_{6},-0.2\right),\left(s_{4},-0.3\right)\right)$ & $\left(\left(s_{6},-0.5\right),\left(s_{4},-0.1\right)\right)$ & $\left(\left(s_{6},-0.3\right),\left(s_{4},-0.3\right)\right)$ \\
\hline & $x_{2}$ & $\left(\left(s_{6}, 0\right),\left(s_{4},-0.1\right)\right)$ & $\left(\left(s_{6}, 0\right),\left(s_{3}, 0\right)\right)$ & $\left(\left(s_{6}, 0\right),\left(s_{4},-0.5\right)\right)$ & $\left(\left(s_{6}, 0\right),\left(s_{4},-0.3\right)\right)$ \\
\hline & $x_{3}$ & $\left(\left(s_{5}, 0\right),\left(s_{4},-0.2\right)\right)$ & $\left(\left(s_{3}, 0.3\right),\left(s_{3}, 0.1\right)\right)$ & $\left(\left(s_{5}, 0.3\right),\left(s_{4},-0.5\right)\right)$ & $\left(\left(s_{4},-0.5\right),\left(s_{4},-0.2\right)\right)$ \\
\hline \multirow[t]{3}{*}{$e_{2}$} & $x_{1}$ & $\left(\left(s_{5}, 0\right),\left(s_{3}, 0\right)\right)$ & $\left(\left(s_{6},-0.2\right),\left(s_{4},-0.5\right)\right)$ & $\left(\left(s_{6}, 0\right),\left(s_{4}, 0\right)\right)$ & $\left(\left(s_{6}, 0\right),\left(s_{2}, 0.5\right)\right)$ \\
\hline & $x_{2}$ & $\left(\left(s_{6},-0.5\right),\left(s_{4},-0.3\right)\right)$ & $\left(\left(s_{6},-0.3\right),\left(s_{2}, 0.4\right)\right)$ & $\left(\left(s_{6}, 0\right),\left(s_{3}, 0\right)\right)$ & $\left(\left(s_{5},-0.5\right),\left(s_{2}, 0.2\right)\right)$ \\
\hline & $x_{3}$ & $\left(\left(s_{6}, 0\right),\left(s_{3}, 0\right)\right)$ & $\left(\left(s_{3}, 0\right),\left(s_{3}, 0.2\right)\right)$ & $\left(\left(s_{5}, 0.5\right),\left(s_{4},-0.3\right)\right)$ & $\left(\left(s_{2},-0.5\right),\left(s_{2}, 0\right)\right)$ \\
\hline \multirow[t]{3}{*}{$e_{3}$} & $x_{1}$ & $\left(\left(s_{4}, 0.3\right),\left(s_{3}, 0\right)\right)$ & $\left(\left(s_{5}, 0.1\right),\left(s_{4}, 0\right)\right)$ & $\left(\left(s_{2}, 0.5\right),\left(s_{4},-0.4\right)\right)$ & $\left(\left(s_{6},-0.3\right),\left(s_{3},-0.2\right)\right)$ \\
\hline & $x_{2}$ & $\left(\left(s_{6},-0.2\right),\left(s_{2}, 0.2\right)\right)$ & $\left(\left(s_{5}, 0.2\right),\left(s_{4},-0.2\right)\right)$ & $\left(\left(s_{6},-0.2\right),\left(s_{3}, 0\right)\right)$ & $\left(\left(s_{3}, 0.4\right),\left(s_{3},-0.1\right)\right)$ \\
\hline & $x_{3}$ & $\left(\left(s_{5}, 0\right),\left(s_{3},-0.5\right)\right)$ & $\left(\left(s_{2}, 0.2\right),\left(s_{2}, 0.3\right)\right)$ & $\left(\left(s_{5},-0.5\right),\left(s_{1}, 0.3\right)\right)$ & $\left(\left(s_{2}, 0.2\right),\left(s_{2}, 0\right)\right)$ \\
\hline \multirow[t]{3}{*}{$e_{4}$} & $x_{1}$ & $\left(\left(s_{6},-0.5\right),\left(s_{3},-0.4\right)\right)$ & $\left(\left(s_{6},-0.5\right),\left(s_{4},-0.5\right)\right)$ & $\left(\left(s_{5}, 0\right),\left(s_{4},-0.3\right)\right)$ & $\left(\left(s_{5}, 0\right),\left(s_{3}, 0\right)\right)$ \\
\hline & $x_{2}$ & $\left(\left(s_{6}, 0\right),\left(s_{3},-0.2\right)\right)$ & $\left(\left(s_{6}, 0\right),\left(s_{3},-0.5\right)\right)$ & $\left(\left(s_{6}, 0\right),\left(s_{4},-0.1\right)\right)$ & $\left(\left(s_{5},-0.4\right),\left(s_{2},-0.3\right)\right)$ \\
\hline & $x_{3}$ & $\left(\left(s_{4}, 0\right),\left(s_{2}, 0\right)\right)$ & $\left(\left(s_{2}, 0\right),\left(s_{2}, 0\right)\right)$ & $\left(\left(s_{2}, 0\right),\left(s_{2},-0.5\right)\right)$ & $\left(\left(s_{1}, 0\right),\left(s_{1},-0.1\right)\right)$ \\
\hline \multirow[t]{3}{*}{$e_{5}$} & $x_{1}$ & $\left(\left(s_{5},-0.2\right),\left(s_{3},-0.1\right)\right)$ & $\left(\left(s_{6},-0.5\right),\left(s_{3}, 0.2\right)\right)$ & $\left(\left(s_{5}, 0\right),\left(s_{3}, 0\right)\right)$ & $\left(\left(s_{4}, 0\right),\left(s_{2}, 0\right)\right)$ \\
\hline & $x_{2}$ & $\left(\left(s_{6},-0.2\right),\left(s_{2}, 0\right)\right)$ & $\left(\left(s_{6}, 0\right),\left(s_{2},-0.1\right)\right)$ & $\left(\left(s_{6}, 0\right),\left(s_{3},-0.5\right)\right)$ & $\left(\left(s_{3},-0.5\right),\left(s_{2}, 0.3\right)\right)$ \\
\hline & $x_{3}$ & $\left(\left(s_{2}, 0.3\right),\left(s_{1}, 0\right)\right)$ & $\left(\left(s_{3}, 0\right),\left(s_{2},-0.2\right)\right)$ & $\left(\left(s_{3}, 0\right),\left(s_{2}, 0\right)\right)$ & $\left(\left(s_{4}, 0\right),\left(s_{4}, 0\right)\right)$ \\
\hline
\end{tabular}
$\eta_{\sigma(h)} \in(0,1), \quad \sum_{h=1}^{m} \eta_{\sigma(h)}=1$ when gathering individual

Table 1. Evaluation matrix given by the experts. 
decision making information. Let the empathetic attitude parameter $\delta=0.4$.

$$
\begin{aligned}
\eta_{\sigma(h)}^{E C} & =Q\left(\frac{h}{m}\right)-Q\left(\frac{h-1}{m}\right) \\
& =\left(\frac{h}{m}\right)^{0.4}-\left(\frac{h-1}{m}\right)^{0.4}
\end{aligned}
$$

The weights ordered by induced values are: $\eta_{\sigma(1)}^{E C}=0.5253, \eta_{\sigma(2)}^{E C}=0.1678 \quad \eta_{\sigma(3)}^{E C}=0.1220 \quad \eta_{\sigma(4)}^{E C}=0.0994 \quad \eta_{\sigma(5)}^{E C}=0.0853$

and the corresponding weights in the process of gathering individual decision information are: $\eta_{1}^{E C}=0.1678, \eta_{2}^{E C}=0.1220 \quad \eta_{3}^{E C}=0.5253 \quad \eta_{4}^{E C}=0.0994 \quad \eta_{5}^{E C}=0.0853$

Calculate the group decision making matrix according to Equation (12) and Equation (13) to obtain the evaluation of the 2-dimension 2-tuple linguistic information of group decision making.

Step 2. Calculate the distance between each expert's decision making matrix and the group decision making matrix according to Equation (15).

This section defines $d\left(S^{c}, S^{k}\right)$ as the Hamming distance, $\lambda=1, \quad \varepsilon=0.7 . d\left(S^{c}, S^{1}\right)=0.0572$, $d\left(S^{c}, S^{2}\right)=0.0945, d\left(S^{c}, S^{1}\right)=0.1391, d\left(S^{c}, S^{1}\right)=0.2885$ and $d\left(S^{c}, S^{1}\right)=0.3316$.

Step 3. Calculate the group consensus level $G C I^{(1)}$ according to Equation (16)-Equation (18).

Calculate the individual consensus level of experts according to Eq. (16): $C I_{1}=0.9428, C I_{2}=0.9055$, $C I_{3}=0.8609, C I_{4}=0.7115$, and $C I_{5}=0.6684$.

The expert weights are calculated according to equation (17): $\eta_{1}=0.2108, \eta_{2}=0.2035, \eta_{3}=0.3231$, $\eta_{4}=1607$, and $\eta_{5}=0.1017$.

The group consensus level is calculated according to Equation (18)

$$
G C I^{(0)}=\sum_{k=1}^{m} \eta_{k} C I_{k}=0.8436
$$

Let the threshold value $\tau=0.9$, obviously, $G C I^{(0)} \leq \tau$ which indicates that the group consensus has not reached the preset level, and the feedback mechanism needs to be activated to improve the consensus level.

Step 4. Identify and adjust $e_{k}^{a d j}$ according to Equation (19) and Equation (20).

The identification rule is the member with the smallest individual consensus, i.e., the member with the farthest distance from the group decision making outcome, i.e $e_{5}$.

Adjust $e_{5}$ according to Equation (20). Where, $M_{k}^{l}$ is the decision making matrix of the previous round $e_{5}$, $M_{c}$ is the group decision gathered in step $1, M_{k j}$ is the set of decision information expressed by the empathy object of $e_{5}$, and the empathy relationship comes from $W=\left(w_{i j}\right)_{m \times m} . \theta$ is the feedback adjustment coefficient, $e_{5}$ representing the proportion of their own decision information, which can be expressed with confidence index $\rho_{k}(k=1,2, \ldots, m)$. Obtain the decision making matrix $M_{5}^{(1)}$ after the adjustment of $e_{5}$

Step 5. Let $l=l+1$, go to step 1 .

After 7 iterations, $G C I^{(7)}=0.9001>\tau$, and the group reached consensus. The group decision making matrix at this time is:

Step 6. Calculate the expected value of each plan in the group decision making matrix according to Equation (21)-Equation (23)

After discussion by 5 experts, the weights of the four attributes, laws and policies, corporate responsibility, risk prevention and control, and governance costs are as follows. Use the two-dimensional 2-dimension 2-tuple linguistic information weighted averaging operator to gather the decision information of each plan, and the evaluation value of the plan is:

According to Equation (23), $E_{1}(S)=0.8338$, $E_{2}(S)=0.8165, E_{3}(S)=0.5921$ and the order of the solutions is: $x_{1} \succ x_{2} \succ x_{3}$. That is, city 1 has the strongest environmental governance, city 2 has the second strongest environmental governance capability, and city 3 has the worst environmental governance capability.

\section{Discussion}

The evaluation of environmental governance capacity is a multi-attribute decision-making problem led by the government and participated by all levels of society. There are few evaluation models involving environmental governance capacity in the current research, mainly due to the following points. Firstly, in the actual decision-making process, it is difficult for evaluation experts to have a comprehensive understanding of environmental governance capacity because of its complexity and versatility. Secondly, the invited evaluation experts are different in knowledge structure, professional background and so

Table 2. Group decision making matrix $(l=0)$.

\begin{tabular}{|c|c|c|c|c|c|}
\hline & & $c_{1}$ & $c_{2}$ & $c_{3}$ & $c_{4}$ \\
\hline \multirow{2}{*}{$e_{1}$} & $x_{1}$ & $\left(\left(s_{5}, 0.2\right),\left(s_{4},-0.5\right)\right)$ & $\left(\left(s_{6},-0.3\right),\left(s_{4},-0.2\right)\right)$ & $\left(\left(s_{5}, 0.4\right),\left(s_{4},-0.3\right)\right)$ & $\left(\left(s_{6},-0.4\right),\left(s_{3}, 0.2\right)\right)$ \\
\cline { 2 - 6 } & $x_{2}$ & $\left(\left(s_{6},-0.1\right),\left(s_{3}, 0.4\right)\right)$ & $\left(\left(s_{6},-0.1\right),\left(s_{3}, 0.1\right)\right)$ & $\left(\left(s_{6}, 0\right),\left(s_{4},-0.5\right)\right)$ & $\left(\left(s_{5}, 0\right),\left(s_{3}, 0\right)\right)$ \\
\cline { 2 - 6 } & $x_{3}$ & $\left(\left(s_{5}, 0.2\right),\left(s_{3}, 0.1\right)\right)$ & $\left(\left(s_{3}, 0\right),\left(s_{3},-0.2\right)\right)$ & $\left(\left(s_{5},-0.2\right),\left(s_{3}, 0\right)\right)$ & $\left(\left(s_{3}, 0.2\right),\left(s_{3}, 0\right)\right)$ \\
\hline
\end{tabular}


Table 3. The adjusted decision matrix $M_{5}^{(1)}(l=1)$.

\begin{tabular}{|c|c|c|c|c|c|}
\hline & & $c_{1}$ & $c_{2}$ & $c_{3}$ & $c_{4}$ \\
\hline \multirow{2}{*}{$e_{5}^{(1)}$} & $x_{1}$ & $\left(\left(s_{5}, 0\right),\left(s_{3}, 0.2\right)\right)$ & $\left(\left(s_{6},-0.5\right),\left(s_{4},-0.4\right)\right)$ & $\left(\left(s_{5},-0.1\right),\left(s_{3}, 0.3\right)\right)$ & $\left(\left(s_{5}, 0.2\right),\left(s_{3},-0.2\right)\right)$ \\
\cline { 2 - 6 } & $x_{2}$ & $\left(\left(s_{6},-0.2\right),\left(s_{3},-0.1\right)\right)$ & $\left(\left(s_{6},-0.2\right),\left(s_{3},-0.5\right)\right)$ & $\left(\left(s_{6}, 0\right),\left(s_{3}, 0.1\right)\right)$ & $\left(\left(s_{4}, 0\right),\left(s_{3},-0.3\right)\right)$ \\
\cline { 2 - 6 } & $x_{3}$ & $\left(\left(s_{4}, 0.4\right),\left(s_{2}, 0.4\right)\right)$ & $\left(\left(s_{3},-0.2\right),\left(s_{3},-0.5\right)\right)$ & $\left(\left(s_{4}, 0.2\right),\left(s_{3},-0.5\right)\right)$ & $\left(\left(s_{3}, 0\right),\left(s_{3},-0.3\right)\right)$ \\
\hline
\end{tabular}

Table 4. Group decision making matrix $M_{c}^{(7)}(l=7)$.

\begin{tabular}{|c|c|c|c|c|c|}
\hline & & $c_{1}$ & $c_{2}$ & $c_{3}$ & $c_{4}$ \\
\hline \multirow{2}{*}{$M_{c}^{(7)}$} & $x_{1}$ & $\left(\left(s_{5}, 0.1\right),\left(s_{4},-0.4\right)\right)$ & $\left(\left(s_{6},-0.3\right),\left(s_{4},-0.1\right)\right)$ & $\left(\left(s_{5}, 0.3\right),\left(s_{4},-0.1\right)\right)$ & $\left(\left(s_{6},-0.1\right),\left(s_{3}, 0.3\right)\right)$ \\
\cline { 2 - 6 } & $x_{2}$ & $\left(\left(s_{6},-0.1\right),\left(s_{4},-0.5\right)\right)$ & $\left(\left(s_{6},-0.2\right),\left(s_{3}, 0.4\right)\right)$ & $\left(\left(s_{6}, 0\right),\left(s_{3}, 0.3\right)\right)$ & $\left(\left(s_{5}, 0.2\right),\left(s_{3}, 0.3\right)\right)$ \\
\cline { 2 - 6 } & $x_{3}$ & $\left(\left(s_{6},-0.4\right),\left(s_{3}, 0.4\right)\right)$ & $\left(\left(s_{3}, 0\right),\left(s_{3}, 0\right)\right)$ & $\left(\left(s_{5}, 0.2\right),\left(s_{3}, 0.2\right)\right)$ & $\left(\left(s_{3},-0.1\right),\left(s_{3}, 0.1\right)\right)$ \\
\hline
\end{tabular}

on. In addition, the actual decision-making process is an open environment, so the evaluation experts are not completely independent. There may be a certain social relationship between them, and it is very difficult for the evaluation experts to make a completely rational judgment. In short, such decision making problems are more or less affected by a series of factors such as feelings and social relations. The decision-making information given by evaluation experts in the form of scoring and ranking is likely to be processed and does not necessarily reflect their most real ideas.

The contribution of this paper is that the evaluation of environmental governance capacity is regarded as a social network group decision making problem. Firstly, language information, that is, 2-dimension 2-tuple linguistic information, is used to express the opinions of evaluation experts, which can better reflect the most real, direct and accurate ideas of evaluation experts. Second, this paper uses empathetic relations to describe the social relationship between experts. Empathy reflects the individual's understanding of others' emotions and attention to others' welfare. This description can reflect the phenomena of "influential people" or "Irrational influence on experts" in the decision-making process. Thirdly, this paper introduces

Table 5. Evaluation by Group.

\begin{tabular}{|c|c|}
\hline & $c_{1}$ \\
\hline$x_{1}$ & $\left(\left(s_{5}, 0.4\right),\left(s_{4},-0.3\right)\right)$ \\
\hline$x_{2}$ & $\left(\left(s_{6},-0.2\right),\left(s_{3}, 0.4\right)\right)$ \\
\hline$x_{3}$ & $\left(\left(s_{4}, 0.4\right),\left(s_{3}, 0.2\right)\right)$ \\
\hline
\end{tabular}

the concept of confidence index to improve the rationality and accuracy of decision-making results. Different impressions are given by confident evaluation experts and non confident experts when expressing views. This improvement makes the decision-making results more in line with the actual situation.

In terms of theoretical significance, the model proposed in this paper is an extension of the social network group decision-making model, it discusses the consensus reaching process considering the confidence level of decision makers in the language environment. In terms of application value, there are few models involved in the evaluation of environmental governance capacity in the current research. The method proposed in this article considers the characteristics of environmental governance capability evaluation issues and similar government-led evaluation issues, such as diverse personnel structure, complex social network, multiple evaluation attributes, etc. The model can reflect the real opinions of evaluation experts, and the solution process is more convenient. The example analysis proves the effectiveness and scientificity of the method. Therefore, the evaluation model proposed in this paper is easy to implement and popularize, and it provides a new way for the evaluation of environmental governance capacity, so that it has certain practical significance.

\section{Conclusion}

The assessment of environmental governance capacity involves experts from different backgrounds, who have different expression habits, social relations and influence, which have great influence on consensus and decision-making. It is a challenge for us to use 
the information that can express experts' opinions truly and accurately, to integrate the information index of experts' psychological changes, and to determine the social network that can reflect the relationship between experts.

Based on this, this paper proposes an environmental governance capability evaluation model, which can solve the above problems, this is a consensus model for group decision making of 2-dimension 2-tuple linguistic information based on empathetic relations. The steps to reach consensus and make decisions are as follows: (1) The model uses 2-dimension 2-tuple linguistic information to express decision making information, uses empathetic relations to build social networks, and uses empathy centrality to describe the influence of experts. (2) On this basis, The confidence index is first constructed by using linguistic information, and the confidence index is used to adjust the empathetic centrality so that the empathetic centrality is incorporated into the expert psychological change factors. (3) Then, the expert decision information is gathered by using empathetic centrality as the induced value. The group consensus level is calculated by measuring the distance between individuals and groups, and a consensus adjustment method is established by using the confidence index. (4) Then the evaluation results are obtained by using a 2-dimension 2-tuple linguistic information weighted averaging operator to process the group decision information that reaches consensus. (5) Finally, the feasibility and effectiveness of the method is analyzed by using an example of the evaluation of environmental governance capacity. The results of case show that the model proposed in this paper can solve the problem of environmental governance capacity evaluation.

The evaluation of environmental governance capacity in the real world is much more complex than what we discussed. In the following research, we will improve in the following aspects: (1) the clustering method can be used to extend the research results of this paper to large group decision-making with more than 20 people, so as to enrich the application scenarios of environmental governance capacity evaluation. (2) In the future, the parameters in the model will be studied to explore the selection of optimal parameters. (3) We will conduct further study into the rational establishment of social relations.

\section{Acknowledgments}

This research was supported by the National Natural Science Foundation of China (Grant nos. 61773123).

\section{Conflict of Interest}

The authors declare no conflict of interest.

\section{References}

1. WEI CUIPING., MA JING. A consensus model for hesitant and vague linguistic group decision making. Control and decision making, 33 (2), 275, 2018 [In Chinese].

2. TANG M., LIAO H., MI X., LEV B., PEDRYCZ W. A hierarchical consensus reaching process for group decision making with noncooperative behaviors. European Journal of Operational Research, 293 (2), 632, 2021.

3. WAN S., ZHONG L., DONG J. A new method for group decision making with hesitant fuzzy preference relations based on multiplicative consistency. IEEE Transactions on Fuzzy Systems, 28 (7), 1449, 2019.

4. DONG Y., ZHA Q., ZHANG H., HERRERA F. Consensus Reaching and Strategic Manipulation in Group Decision Making With Trust Relationships. IEEE Transactions on Systems, Man, and Cybernetics: Systems, 99 (1), 15, 2020.

5. RODRÍGUEZ R., LABELLA L., SESMA-SARA M., BUSTINCE H., MARTÍNEZ L. A Cohesion-driven Consensus Reaching Process for Large Scale Group Decision Making under a Hesitant Fuzzy Linguistic Term Sets Environment. Computers \& Industrial Engineering, 155 (2021), 107158, 2021.

6. CHANG CHIA-HAO, CHEN SHYI-MING A novel similarity measure between Atanassov's intuitionistic fuzzy sets based on transformation techniques with applications to pattern recognition. Information Sciences, 291 (2015), 96, 2015.

7. CHENG S.H., CHEN S.M., LAN T.C. A novel similarity measure between intuitionistic fuzzy sets based on the centroid points of transformed fuzzy numbers with applications to pattern recognition. Information Sciences, 343 (2016), 15, 2016.

8. DIYAR, AKAY, FATIH, EMRE, BORAN A biparametric similarity measure on intuitionistic fuzzy sets with applications to pattern recognition. Information Sciences An International Journal, 255 (2014), 45, 2014.

9. FENG SHEN, XINSONG MA, ZHIYONG LI, ZESHUI XU, DONGLIANG CAI An extended intuitionistic fuzzy TOPSIS method based on a new distance measure with an application to credit risk evaluation. Information Sciences, 428 (2018), 105, 2018.

10. REN JIAN, WANG JIANQIANG, HU CHUNHUA A multi-criteria group decision making method for normal clouds based on cosine closeness and group consensus. Control and decision making, 32 (4), 665, 2017 [In Chinese].

11. LV JINHUI, GUO SICONG, GUO FANGFANG Hesitant and vague information similarity measure with group consistency measure and group decision making application. Control and decision, 35 (8), 1987, 2020. [In Chinese].

12. ZHANG X., XU Z. Soft computing based on maximizing consensus and fuzzy TOPSIS approach to interval-valued intuitionistic fuzzy group decision making. Applied Soft Computing, 26 (2015), 42, 2015.

13. ZHANG SHITAO, ZHU JIANJUN, LIU XIAODI A multigranular language consensus model based on importanceguided preference recognition and correction. Control and decision, 30 (9), 1609, 2015 [In Chinese].

14. CHU J., WANG Y., LIU X., LIU Y. Social network community analysis based large-scale group decision making approach with incomplete fuzzy preference relations. Information Fusion, 60 (2020), 98, 2020. 
15. TAN X., ZHU J., ZHANG Y. A Consensus Reaching Process with Quantum Subjective Adjustment in Linguistic Group Decision Making. Information Sciences, 533 (2020), 150, 2020.

16. FAN C., ZHU Y., LI W., ZHANG H. Consensus building in linguistic failure mode and effect analysis: A perspective based on prospect theory. Quality and Reliability Engineering International, 36 (8), 2521, 2020.

17. CABRERIZO F.J., MORENO J.M., PÉREZ I., HERRERAVIEDMA E. Analyzing consensus approaches in fuzzy group decision making: advantages and drawbacks. Soft Computing, 14(6), 451, 2010.

18. WU Z., JIN B., XU J. Local feedback strategy for consensus building with probability-hesitant fuzzy preference relations. Applied Soft Computing, 67 (2018), 691, 2018.

19. CAO M., WU J., CHICLANA F., URENA R., HERRERAVIEDMA E. A Personalized Consensus Feedback Mechanism Based on Maximum Harmony Degree. IEEE Transactions on Systems, Man, and Cybernetics: Systems, 52 (1), 13, 2020.

20. WU J., DAI L., CHICLANA F., FUJITA H., HERRERAVIEDMA E. A minimum adjustment cost feedback mechanism based consensus model for group decision making under social network with distributed linguistic trust. Information Fusion, 41 (2018), 232, 2018.

21. BEN-ARIEH D., EASTON T. Multi-criteria group consensus under linear cost opinion elasticity. Decision Support Systems, 43 (2007), 713, 2007.

22. DONG Y., CHEN X., HERRERA F. Minimizing adjusted simple terms in the consensus reaching process with hesitant linguistic assessments in group decision making. Information Sciences, 297 (2015), 95, 2015.

23. ZHANG B., LIANG H., ZHANG G. Reaching a consensus with minimum adjustment in MAGDM with hesitant fuzzy linguistic term sets. Information Fusion, 42 (2018), 12, 2017.

24. JIAN W.A., QI S.A., HF B., D, F. An attitudinal consensus degree to control the feedback mechanism in group decision making with different adjustment cost. Knowledge-Based Systems, 164 (2019), 265, 2019.

25. ZHANG H., DONG Y., CHICLANA F., YU S. Consensus efficiency in group decision making: A comprehensive comparative study and its optimal design. European Journal of Operational Research, 275 (2019), 580, 2019.

26. SINGER T. The neuronal basis and ontogeny of empathy and mind reading: Review of literature and implications for future research. Neurosci Biobehav Rev, 30 (6), 855, 2006.

27. YAO SHENGBAO, GU MIAO Research on group consensus decision model under the influence of empathetic relations. Chinese management science, 9 (7), 11, 2020 [In Chinese].

28. SALEHI-ABARI A., BOUTILIER C., LARSON K. Empathetic decision making in social networks. Artificial intelligence, 275 (2019), 174, 2019

29. ZADEH L.A. The concept of a linguistic variable and its application to approximate reasoning. Information Sciences, 8 (11), 199, 1975.

30. HERRERA F., MARTINEZ L., MARTÍNEZ L. A 2-Tuple Fuzzy Linguistic Representation Model for Computing with Words. IEEE Transactions on Fuzzy Systems, 8 (6), 746, 2000.

31. ZHU WEIDONG., ZHOU GUANGZHONG., YANG SHANLIN. Group decision-making method based on 2-dimension language evaluation information. Systems engineering, 27 (2), 113, 2009 [In Chinese].

32. YANG Y., KHAN A. Exploring the role of finance, natural resources, and governance on the environment and economic growth in South Asian countries. Environmental Science and Pollution Research, 7 (5), 15, 2021.

33. SHADDADY A. Business environment, political risk, governance, Shariah compliance and efficiency in insurance companies in the MENA region. The Geneva Papers on Risk and Insurance - Issues and Practice, 8 (5), 44, 2021.

34. ZHENG SIQI, WAN GUANGHUA, SUN WEIZENG, LUO DANGLUN Public appeals and urban environmental governance. Management world, 6 (6), 72, 2013 [In Chinese].

35. LYNCH D., LATHOURAS A., FORDE C. Community development and social work teaching and learning in a time of global interruption. Community Development Journal, 28 (8), 21, 2021.

36. SHEN D., XIA M., ZHANG Q., ELAHI E., ZHOU Y., ZHANG H. The impact of public appeals on the performance of environmental governance in China: A perspective of provincial panel data. Journal of Cleaner Production, 231 (2019), 290, 2019.

37. MUSTALAHTI The responsive bioeconomy: The need for inclusion of citizens and environmental capability in the forest based bioeconomy. Journal of Cleaner Production, 172 (2018), 3781, 2018.

38. MALIN SONG, SHAOPENG CAO, SHUHONG WANG The impact of knowledge trade on sustainable development and environment-biased technical progress. Technological Forecasting and Social Change, 144 (2019), 512, 2019.

39. HSU A., RAUBER R. Diverse climate actors show limited coordination in a large-scale text analysis of strategy documents. Communications Earth \& Environment, 2 (1), 12, 2021.

40. ORTAKAVAK Z., CABUK S.N.,CETIN M., SENYEL KURKCUOGLU M.A., CABUK A. Determination of the nighttime light imagery for urban city population using DMSP-OLS methods in Istanbul. Environ Monit Assess, 192 (12), 790, 2020.

41. CETIN M., AKSOY T., CABUK S.N., SENYEL KURKCUOGLU M.A., CABUK A. Employing remote sensing technique to monitor the influence of newly established universities in creating an urban development process on the respective cities. Land Use Policy, 109 (2021), 105705, 2021.

42. CETIN M., AGACSAPAN B., CABUK S.N., SENYEL KURKCUOGLU M.A., ISIK PEKKAN O., BARAN ARGUN E., DABANLI A., KUCUKPEHLIVAN T., YILMAZEL B., CABUK A. Assessment of the Ecological Footprint of Eskisehir Technical University-Iki Eylul Campus. Journal of the Indian Society of Remote Sensing, 49 (10), 2311, 2021.

43. KAYA E., AGCA M., ADIGUZEL F., CETIN M. Spatial data analysis with $\mathrm{R}$ programming for environment. Human and Ecological Risk Assessment: An International Journal, 25 (6), 1521, 2018.

44. ZHU H., ZHAO J., XU Y. 2-dimension linguistic computational model with 2-tuples for multi-attribute group decision making. Knowledge-Based Systems, 103 (2016), 132, 2016.

45. LABELLA A., LIU Y., RODRIGUEZ R.M., MARTINEZ L. Analyzing the performance of classical consensus models in large scale group decision making: 
A comparative study. Applied Soft Computing, 67 (2018), 677, 2018.

46. LIU Y., FAN Z.P., ZHANG X. A method for large group decision-making based on evaluation information provided by participators from multiple groups. Information Fusion, 29 (2016), 132, 2016.

47. PALOMARES I., MARTINEZ L., HERRERA F. A Consensus Model to Detect and Manage Noncooperative Behaviors in Large-Scale Group Decision Making. IEEE Transactions on Fuzzy Systems, 22 (3), 516, 2014.

48. WU Z., XU J. A consensus model for large-scale group decision making with hesitant fuzzy information and changeable clusters. Information Fusion, 41 (2018), 217, 2018.

49. XU X., DU Z., CHEN X.H., CAI C. Confidence consensusbased model for large-scale group decision making: A novel approach to managing non-cooperative behaviors. Information Sciences, 477 (2019), 410, 2019.
50. YANG L., FAN Z.P., YOU T.H., ZHANG W.Y. Large group decision-making (LGDM) with the participators from multiple subgroups of stakeholders: A method considering both the collective evaluation and the fairness of the alternative. Computers \& Industrial Engineering, 122 (2018), 262, 2018.

51. YAGER R.R. Quantifier guided aggregation using OWA operators. International Journal of Intelligent Systems, 11 (1), 49, 1996.

52. WANG ZELIN, WANG YINGMING 2-dimension 2-tuple linguistic information multi-attribute group decisionmaking method with completely unknown weight information. Control and decision. 34 (9), 194, 2019 [In Chinese].

53. LIU P., YU X. 2-Dimension uncertain linguistic power generalized weighted aggregation operator and its application in multiple attribute group decision making. Knowledge-Based Systems, 57 (2014), 69, 2014. 